\title{
Diabetic kidney disease - state-of-the-art knowledge in 2020
}

\section{ABSTRACT}

Diabetic kidney disease is one of the most common complications of diabetes. For many years, it has also been the most common cause of end stage renal disease. The diagnosis of DKD is based on determining the urinary albumin-to-creatinine ratio and calculating the estimated glomerular filtration rate. Recently, the disease phenotype has changed and instead of the classical diabetic kidney disease presentation characterized by albuminuria followed by progressive renal failure, patients nowadays more often present only with reduced eGFR but normal urinary albumin excretion. The nephroprotective properties of new antidiabetic drugs, such as sodium-glucose co-transporter- 2 inhibitors and glucagon-like peptide-1 analogues, are the novelty of recent years. Moreover, there are ongoing outcome trials with renal safety as the primary endpoint, and their results may extend the knowledge about using antidiabetic drugs for renal risk reduction not only in patients with diabetes but also in those without carbohydrate metabolism disorders. (Clin Diabetol 2020; 9; 3: 184-188)

Key words: diabetes mellitus, diabetic kidney disease, microangiopathy

\footnotetext{
Address for correspondence: lek. Hanna Kwiendacz

Katedra i Klinika Chorób Wewnętrznych, Diabetologii i Nefrologii Wydział Nauk Medycznych w Zabrzu

Śląski Uniwersytet Medyczny w Katowicach

ul. 3 Maja 13-15, 41-800 Zabrze

Phone +48 323704 488, fax: +48 323704489

e-mail: hanna.kwiendacz@gmail.com

Translation: dr n. med. Piotr Jędrusik

Clinical Diabetology 2020, 9, 3, 184-188

DOI: $10.5603 /$ DK.2020.0019

Received: 30.04 .2020

Accepted: 12.05 .2020
}

\section{Introduction}

Over the last several decades, diabetic kidney disease (DKD) has become the major cause of end stage renal disease (ESRD) in the developed countries $[1,2]$. This microangiopathic complication of diabetes develops in about $30 \%$ of patients with type 1 diabetes mellitus (T1DM) and about $40 \%$ of patients with type 2 diabetes mellitus (T2DM) [1, 3]. An increased DKD incidence reflects a dramatic rise in the number of diabetic patients, and therefore diabetes has been dubbed the non-infectious epidemics of the $21^{\text {st }}$ century [4]. It has been estimated that in 2017 the number of adults with diabetes worldwide was 451 million (including more than 2.2 million in Poland), and this number is predicted to increase to 693 million by 2045 [5]. The natural history of DKD was believed to begin with hyperfiltration followed by microalbuminuria, overt albuminuria, and reduction in the glomerular filtration rate, ultimately leading to ESRD [6], but in the recent years, it has been questioned as this complication has become increasingly heterogeneous. It is currently believed that the phenotype of DKD evolves, with an increasing number of patients with T2DM who present with a reduced estimated glomerular filtration rate (eGFR) without concomitant albuminuria [7]. In addition, the development of DKD in both T1DM [8] and T2DM [9] is associated with an increased cardiovascular event rate and mortality. Thus, a reduction in the risk of DKD's occurance and/or its progression is vital for reducing the risk of both cardiovascular mortality and the development of ESRD requiring renal replacement therapy. The conventional multifactorial approach to the management of DKD includes lifestyle modifications, optimal control of diabetes, blood pressure and lipid profile, and the use of renin-angiotensin-aldosterone (RAA) system inhibitors. Recently, however, large cardiovascular outcome trials (CVOT) of new antidiabetic drugs, such as sodium-glucose co-transporter-2 (SGLT2) inhibitors and 
glucagon-like peptide-1 (GLP-1) analogues, have shed a new light on the benefits of these drugs for the reduction of not only cardiovascular but also renal risk [10].

The present article discusses the most important aspects of DKD diagnosis and management based on the evidence reported in recent years.

\section{Diagnosis of DKD}

As DKD remains asymptomatic for a long time, an extremely important aspect of managing diabetic patients is screening for DKD, which should be repeated annually since the diagnosis of T2DM and starting from 5 years after the diagnosis of T1DM [11]. The diagnosis of DKD is based on the clinical evaluation including the presence of albuminuria and a reduced eGFR [11]. Currently, the preferred approach to the evaluation for albuminuria is a measurement of the urinary albumin-to-creatinine ratio (UACR) $[11,12]$ in a spot urine sample, preferably collected in the morning hours. The Chronic Kidney Disease Epidemiology Collaboration (CKD-EPI) formula should be used for eGFR calculations [12-14]. Large cross-sectional studies showed that many patients with T2DM and a reduced eGFR had normal urinary albumin excretion. In these studies, the proportion of subjects with normoalbuminuria despite a reduced eGFR $\left(<60 \mathrm{~mL} / \mathrm{min} / 1.73 \mathrm{~m}^{2}\right)$ ranged from $16 \%$ to $33 \%$ [15-18]. These observations were also confirmed in patients with T1DM [19], with the proportion of patients with normoalbuminuria and a reduced eGFR up to as much as $50-60 \%$ in some studies [20-22]. The proposed explanations include improved blood glucose and blood pressure control, and a widespread use of RAA system inhibitors [23]. Thus, although the rate of ESRD in diabetes has not changed, the DKD phenotype evolved from a classical one, associated with albuminuria, to the one with normal urinary albumin excretion observed in some patients [24]. Also of note, the rate of nondiabetic chronic kidney disease (CKD) has increase secondary to an increasing mean life expectancy, unhealthy lifestyle, and more frequent acute kidney injury events of both ischaemic and toxic aetiology [25-27]. Due to these factors, CKD in diabetic patients is partially related to the presence of non-diabetic kidney disease. Thus, CKD in diabetic patients may be "pure" DKD (resulting from diabetes per se), non-diabetic kidney disease, or a combination of diabetic and non-diabetic kidney disease, and these types may be truly distinguished only based on renal biopsy findings [28]. In the largest study to date that evaluated renal biopsy samples in patients with T2DM, including 620 patients with the mean diabetes duration of 10 years, DKD was identified in $37 \%$ of renal biopsy samples, non-diabetic kidney disease in $36 \%$, and concomitant diabetic and non-diabetic kidney disease in $27 \%$ [29]. However, renal biopsy, although considered a diagnostic gold standard, is not a routine diagnostic method in the evaluation of DKD and thus for the statistical and registry purposes, patients are generally categorized as having DKD if they have been diagnosed with both diabetes and CKD.

\section{Management of DKD}

The major issue in diabetes is to define the principles of a long-term, safe, well-tolerated and effective therapy in patients with a varying degree of vascular complications. Antidiabetic drugs, in particular new molecules, should not only affect blood glucose control but also contribute to a reduction in cardiovascular and renal morbidity and mortality. For this reason, the U.S. Food and Drug Administration's (FDA) scientific advisory committee published a document in December 2008 that mandated the need for cardiovascular risk assessment (performing CVOT) for all the novel antidiabetic drugs. These studies must be powered to show no excess cardiovascular and renal risk (i.e., prove cardiovascular and renal safety) of antidiabetic drugs compared to placebo. As CKD, and in particular DKD, is associated with an increased cardiovascular risk and mortality in both T1DM [8] and T2DM [9], the goal of the therapy includes both reducing progression of DKD and preventing the development of cardiovascular disease [31]. To achieve these goals, a multifactorial approach to the management of DKD should include lifestyle modifications and optimal control of blood glucose, blood pressure (including use of RAA system inhibitors) and lipid profile [32-34]. Until recently, RAA system inhibitors were the only drugs with proven nephroprotective properties [35, 36]. However, their use continued to be associated with a high residual risk of DKD progression and the development of ESRD [37]. This stagnation in the area of nephroprotection in DKD has ended with the results of CVOT of SGLT2 inhibitors and GLP-1 analogues [38-44]. Of SGLT2 inhibitors, cardiovascular benefits were proven for dapagliflozin, empagliflozin, and canagliflozin in the following studies respectively: the Dapagliflozin Effect on Cardiovascular Events-Thrombolysis in Myocardial Infarction 58 (DECLARE-TIMI 58) study, the Empagliflozin Cardiovascular Outcome Event Trial in Type 2 Diabetes Mellitus Patients (EMPA-REG OUTCOME), and the Canagliflozin Cardiovascular Assessment Study (CANVAS) [38-40]. These studies evaluated predefined endpoints in T2DM patients with coronary artery disease or at high cardiovascular risk. In addition to a significant reduction of the combined primary endpoint of cardiovascular death, non-fatal myocardial infarction, and non-fatal stroke, 
a significant reduction in hospitalization due to heart failure and a significant nephroprotective effects was shown, with a relative risk reduction of renal disease progression by about $40 \%$. To further substantiate these very promising results in regard to nephroprotection, subsequent studies with these drugs were designed with the primary endpoint of renal disease progression. These include: the Dapagliflozin And Prevention of Adverse Outcomes in Chronic Kidney Disease (DAPA-CKD) study [45], The Study of Heart and Kidney Protection With Empagliflozin (EMPA-KIDNEY) [46], and the Canagliflozin and Renal Outcomes in Type 2 Diabetes and Nephropathy (CREDENCE) study [47]. One of these studies, the CREDENCE trial with canagliflozin, was terminated earlier than planned due to a proven independent nephroprotective effect of the drug, and the results were published in April 2019. Canagliflozin treatment was shown to result in a significant reduction of the primary combined endpoint that included ESRD (defined as the need for dialysis therapy or kidney transplantation, or persistent eGFR reduction to $<15$ $\mathrm{mL} / \mathrm{min} / 1.73 \mathrm{~m}^{2}$ ), doubling of serum creatinine, and renal or cardiovascular death. Several months later, in September 2019, FDA approved canagliflozin for the prevention of ESRD, doubling of serum creatinine, cardiovascular mortality, and hospitalizations due to heart failure in patients with T2DM, DKD, and albuminuria $>300 \mathrm{mg} / \mathrm{d}$ [48]. The newest SGLT2 inhibitor available in Poland is ertugliflozin, and its CVOT, the Cardiovascular Outcomes Following Ertugliflozin Treatment in Type 2 Diabetes Mellitus Participants With Vascular Disease (VERTIS CV) study, is currently underway. Regarding GLP-1 analogues, CVOT which first showed nephroprotective properties of these drugs based on the assessment of secondary endpoints included: the Liraglutide Effect and Action in Diabetes: Evaluation of Cardiovascular Outcome Results (LEADER) study [41], the Semaglutide and Cardiovascular Outcomes in Patients with Type 2 Diabetes (SUSTAIN-6) study [42], and the Dulaglutide and Cardiovascular Outcomes in Type 2 Diabetes (REWIND): A Double-Blind, Randomised Placebo-Controlled Trial [44]. These studies revealed that GLP-1 analogues contribute to a reduced risk of renal function worsening, and their nephroprotective effect is mostly related to a reduction in albuminuria. To date, no studies of GLP-1 analogues have been published that would evaluate a primary endpoint of renal safety (reduced CKD progression, reduced mortality due to renal causes). The only ongoing trial with a GLP-1 analogue that evaluates a primary endpoint of renal safety is A Research Study to See How Semaglutide Works Compared to Placebo in People With Type 2
Diabetes and Chronic Kidney Disease (FLOW), and its results are expected in August 2024 [49].

\section{Summary}

The above evidence of a beneficial effect of SGLT2 inhibitors and GLP-1 analogues on the reduction of cardiovascular and renal risk led to a modification of the therapeutic approach and guidelines on the management of patients with diabetes. The 2018 consensus of the American Diabetes Association (ADA) and the European Association for the Study of Diabetes (EASD) [50] first highlighted the need for combining the previously recommended multifactorial approach based on the results of STENO and STENO 2 (Intensified Multifactorial Intervention in Patients With Type 2 Diabetes and Microalbuminuria) studies $[32,51]$ with treatment individualization based on the presence of cardiovascular disease, CKD, an elevated risk of hypoglycemia, the need for weight reduction, and economic restraints. It should be noted that cardiovascular and renal safety are intrinsically and bidirectionally related and cannot be considered separately. In an update of the 2018 ADA/EASD consensus that was published in December 2019, it was suggested that adding an SGLT2 inhibitor or a GLP-1 analogue to metformin should be considered regardless of baseline $\mathrm{HbA}_{1 c}$ value in T2DM patients at high cardiovascular risk to reduce the risk of major adverse cardiovascular events (MACE), hospitalizations due to heart failure, cardiovascular mortality, and CKD progression, and these recommendations have been echoed in the 2020 Diabetes Poland guidelines [52, 53]. According to them, GLP-1 analogues with proven cardio- and nephroprotective properties should be preferentially used in patients with an atherosclerotic cardiovascular disease, and SGLT2 inhibitors should be preferred in patients with a heart failure and reduced ejection fraction $(<45 \%)$ or CKD (eGFR $30-60 \mathrm{~mL} / \mathrm{min} / 1.73 \mathrm{~m}^{2}$ or UACR $>30 \mathrm{mg} / \mathrm{g}$ ). The 2020 Diabetes Poland guidelines do not recommend using SGLT2 inhibitors in patients with eGFR below 60 $\mathrm{mL} / \mathrm{min} / 1.73 \mathrm{~m}^{2}$ yet. The ongoing trials should clarify in the near future whether these drugs may be indicated for nephroprotection also in primary prevention, and also in subjects without diabetes.

\section{Conflict of interests}

The authors declare to have no conflict of interests.

\section{REFERENCES}

1. Saran R, Robinson B, Abbott K, et al. US Renal Data System 2019 Annual Data Report: Epidemiology of Kidney Disease in the United States. Am J Kidney Dis. 2020; 75(1): A6-A7, doi: 10.1053/J.ajkd.2019.09.003. 
2. Kramer A, Pippias M, Noordzij M, et al. The European Renal Association - European Dialysis and Transplant Association (ERA-EDTA) Registry Annual Report 2015: a summary. Clin Kidney J. 2018; 11(1): 108-122, doi: 10.1093/ckj/sfx149, indexed in Pubmed: 29423210

3. Reutens AT. Epidemiology of diabetic kidney disease. Med Clin North Am. 2013; 97(1): 1-18, doi: 10.1016/j.mcna.2012.10.001, indexed in Pubmed: 23290726.

4. Ginter $E$, Simko V. Type 2 diabetes mellitus, pandemic in 21st century. Adv Exp Med Biol. 2012; 771: 42-50, doi: 10.1007/9781-4614-5441-0_6, indexed in Pubmed: 23393670.

5. Cho NH, Shaw JE, Karuranga S, et al. IDF Diabetes Atlas: Global estimates of diabetes prevalence for 2017 and projections for 2045. Diabetes Res Clin Pract. 2018; 138: 271-281, doi: 10.1016/j. diabres.2018.02.023, indexed in Pubmed: 29496507.

6. Adler Al, Stevens RJ, Manley SE, et al. UKPDS GROUP. Development and progression of nephropathy in type 2 diabetes: the United Kingdom Prospective Diabetes Study (UKPDS 64). Kidney Int. 2003; 63(1): 225-232, doi: 10.1046/j.1523-1755.2003.00712.x, indexed in Pubmed: 12472787.

7. Maclsaac RJ, Panagiotopoulos S, McNeil KJ, et al. Is nonalbuminuric renal insufficiency in type 2 diabetes related to an increase in intrarenal vascular disease? Diabetes Care. 2006; 29(7): 1560-1566, doi: 10.2337/dc05-1788, indexed in Pubmed: 16801579.

8. Orchard TJ, Secrest AM, Miller RG, et al. In the absence of renal disease, 20 year mortality risk in type 1 diabetes is comparable to that of the general population: a report from the Pittsburgh Epidemiology of Diabetes Complications Study. Diabetologia. 2010: 53(11): 2312-2319, doi: 10.1007/s00125-010-1860-3, indexed in Pubmed: 20665208.

9. Afkarian M, Sachs MC, Kestenbaum B, et al. Kidney disease and increased mortality risk in type 2 diabetes. J Am Soc Nephrol. 2013; 24(2): 302-308, doi: 10.1681/ASN.2012070718, indexed in Pubmed: 23362314.

10. Stephens JW, Brown KE, Min T. Chronic kidney disease in type 2 diabetes: Implications for managing glycaemic control, cardiovascular and renal risk. Diabetes Obes Metab. 2020; 22 Suppl 1: 32-45, doi: 10.1111/dom.13942, indexed in Pubmed: 32267078.

11. Microvascular Complications and Foot Care: Standards of Medical Care in Diabetes - 2020. Diabetes Care. 2019; 43(Supplement 1): S135-S151, doi: $10.2337 / \mathrm{dc} 20$-s011.

12. Lamb EJ, Levey AS, Stevens PE. The Kidney Disease Improving Global Outcomes (KDIGO) guideline update for chronic kidney disease: evolution not revolution. Clin Chem. 2013; 59(3): 462-465, doi: 10.1373/clinchem.2012.184259, indexed in Pubmed: 23449698.

13. Levey AS, Stevens LA, Schmid CH, et al. CKD-EPI (Chronic Kidney Disease Epidemiology Collaboration). A new equation to estimate glomerular filtration rate. Ann Intern Med. 2009; 150(9): 604-612, doi: 10.7326/0003-4819-150-9-200905050-00006, indexed in Pubmed: 19414839.

14. Stevens PE, Levin A. Kidney Disease: Improving Global Outcomes Chronic Kidney Disease Guideline Development Work Group Members. Evaluation and management of chronic kidney disease: synopsis of the kidney disease: improving global outcomes 2012 clinical practice guideline. Ann Intern Med. 2013; 158(11): 825-830, doi: 10.7326/0003-4819-158-11-201306040-00007, indexed in Pubmed: 23732715.

15. Dwyer JP, Parving HH, Hunsicker LG, et al. Renal Dysfunction in the Presence of Normoalbuminuria in Type 2 Diabetes: Results from the DEMAND Study. Cardiorenal Med. 2012; 2(1): 1-10, doi: 10.1159/000333249, indexed in Pubmed: 22493597

16. Kramer HJ, Nguyen QD, Curhan G, et al. Renal insufficiency in the absence of albuminuria and retinopathy among adults with type 2 diabetes mellitus. JAMA. 2003; 289(24): 3273-3277, doi: 10.1001/jama.289.24.3273, indexed in Pubmed: 12824208.

17. Penno G, Solini A, Bonora E, et al. Renal Insufficiency And Cardiovascular Events (RIACE) Study Group. Clinical significance of nonalbuminuric renal impairment in type 2 diabetes. J Hypertens.
2011; 29(9): 1802-1809, doi: 10.1097/HJH.0b013e3283495cd6, indexed in Pubmed: 21738053.

18. Thomas MC, Macisaac RJ, Jerums G, et al. Nonalbuminuric renal impairment in type 2 diabetic patients and in the general population (national evaluation of the frequency of renal impairment cO-existing with NIDDM [NEFRON] 11). Diabetes Care. 2009; 32(8): 1497-1502, doi: 10.2337/dc08-2186, indexed in Pubmed: 19470839.

19. Thorn LM, Gordin D, Harjutsalo V, et al. FinnDiane Study Group. The presence and consequence of nonalbuminuric chronic kidney disease in patients with type 1 diabetes. Diabetes Care. 2015; 38(11): 2128-2133, doi: 10.2337/dc15-0641, indexed in Pubmed: 26310691.

20. Penno G, Russo E, Garofolo M, et al. Evidence for two distinct phenotypes of chronic kidney disease in individuals with type 1 diabetes mellitus. Diabetologia. 2017; 60(6): 1102-1113, doi: 10.1007/s00125-017-4251-1, indexed in Pubmed: 28357502.

21. Pacilli A, Viazzi F, Fioretto $P$, et al. AMD-Annals Study Group. Epidemiology of diabetic kidney disease in adult patients with type 1 diabetes in Italy: The AMD-Annals initiative. Diabetes Metab Res Rev. 2017; 33(4), doi: 10.1002/dmrr.2873, indexed in Pubmed: 27935651.

22. Lamacchia O, Viazzi F, Fioretto $P$, et al. Normoalbuminuric kidney impairment in patients with T1DM: insights from annals initiative. Diabetol Metab Syndr. 2018; 10: 60, doi: 10.1186/s13098-0180361-2, indexed in Pubmed: 30083251.

23. Afkarian M, Zelnick LR, Hall YN, et al. Clinical Manifestations of Kidney Disease Among US Adults With Diabetes, 1988-2014. JAMA. 2016; 316(6): 602-610, doi: 10.1001/jama.2016.10924, indexed in Pubmed: 27532915

24. Gregg EW, Li Y, Wang J, et al. Changes in diabetes-related complications in the United States, 1990-2010. N Engl J Med. 2014; 370(16): 1514-1523, doi: 10.1056/NEJMoa1310799, indexed in Pubmed: 24738668.

25. Bello AK, Levin A, Tonelli $M$, et al. Assessment of global kidney health care status. JAMA. 2017; 317(18): 1864-1881, doi: 10.1001/jama.2017.4046, indexed in Pubmed: 28430830

26. Saran R, Robinson B, Abbott KC, et al. US Renal Data System 2016 Annual Data Report: Epidemiology of Kidney Disease in the United States. Am J Kidney Dis. 2017; 69(3 Suppl 1): A7-A8, doi: 10.1053/j.ajkd.2016.12.004, indexed in Pubmed: 28236831.

27. Hill NR, Fatoba ST, Oke JL, et al. Global prevalence of chronic kidney disease - a systematic review and meta-analysis. PLoS One. 2016; 11(7): e0158765, doi: 10.1371/journal.pone.0158765, indexed in Pubmed: 27383068.

28. Fiorentino $M$, Bolignano D, Tesar V, et al. ERA-EDTA Immunonephrology Working Group. Renal biopsy in patients with diabetes: a pooled meta-analysis of 48 studies. Nephrol Dial Transplant. 2017; 32(1): 97-110, doi: 10.1093/ndt/gfw070, indexed in Pubmed: 27190327.

29. Sharma SG, Bomback AS, Radhakrishnan J, et al. The modern spectrum of renal biopsy findings in patients with diabetes. Clin J Am Soc Nephrol. 2013; 8(10): 1718-1724, doi: 10.2215/ CJN.02510213, indexed in Pubmed: 23886566.

30. Pippias M, Kramer A, Noordzij M, et al. The European Renal Association - European Dialysis and Transplant Association Registry Annual Report 2014: a summary. Clin Kidney J. 2017; 10(2): 154-169, doi: 10.1093/ckj/sfx149.

31. Ninomiya T, Perkovic V, de Galan BE, et al. ADVANCE Collaborative Group. Albuminuria and kidney function independently predict cardiovascular and renal outcomes in diabetes. J Am Soc Nephrol. 2009; 20(8): 1813-1821, doi: 10.1681/ASN.2008121270, indexed in Pubmed: 19443635.

32. Gaede $P$, Vedel $P$, Larsen N, et al. Multifactorial intervention and cardiovascular disease in patients with type 2 diabetes. N Engl J Med. 2003; 348(5): 383-393, doi: 10.1056/NEJMoa021778, indexed in Pubmed: 12556541.

33. Gaede $\mathrm{P}$, Lund-Andersen $\mathrm{H}$, Parving $\mathrm{HH}$, et al. Effect of a multifactorial intervention on mortality in type 2 diabetes. $\mathrm{N}$ Engl J Med. 
2008; 358(6): 580-591, doi: 10.1056/NEJMoa0706245, indexed in Pubmed: 18256393.

34. Oellgaard J, Gæde P, Rossing P, et al. Intensified multifactorial intervention in type 2 diabetics with microalbuminuria leads to long-term renal benefits. Kidney Int. 2017; 91(4): 982-988, doi: 10.1016/j.kint.2016.11.023, indexed in Pubmed: 28187983.

35. Brenner BM, Cooper ME, de Zeeuw D, et al. RENAAL Study Investigators. Effects of losartan on renal and cardiovascular outcomes in patients with type 2 diabetes and nephropathy. N Engl J Med. 2001; 345(12): 861-869, doi: 10.1056/NEJMoa011161, indexed in Pubmed: 11565518.

36. Wu HY, Huang JW, Lin HJ, et al. Comparative effectiveness of renin-angiotensin system blockers and other antihypertensive drugs in patients with diabetes: systematic review and bayesian network meta-analysis. BMJ. 2013; 347: f6008, doi: 10.1136/bmj. f6008, indexed in Pubmed: 24157497.

37. Rosolowsky ET, Skupien J, Smiles AM, et al. Risk for ESRD in type 1 diabetes remains high despite renoprotection. J Am Soc Nephrol. 2011; 22(3): 545-553, doi: 10.1136/bmj.f6008.

38. Wanner C, Inzucchi SE, Lachin JM, et al. EMPA-REG OUTCOME Investigators. Empagliflozin and progression of kidney disease in type 2 diabetes. N Engl J Med. 2016; 375(4): 323-334, doi: 10.1056/NEJMoa1515920, indexed in Pubmed: 27299675.

39. Neal B, Perkovic V, Mahaffey KW, et al. CANVAS Program Collaborative Group. Canagliflozin and cardiovascular and renal events in type 2 diabetes. N Engl J Med. 2017; 377(7): 644-657, doi: 10.1056/NEJMoa1611925, indexed in Pubmed: 28605608.

40. Wiviott SD, Raz I, Bonaca MP, et al. DECLARE-TIMI 58 Investigators. Dapagliflozin and cardiovascular outcomes in type 2 diabetes. N Engl J Med. 2019; 380(4): 347-357, doi: 10.1056/ NEJMoa1812389, indexed in Pubmed: 30415602.

41. Marso SP, Daniels GH, Brown-Frandsen K, et al. LEADER Steering Committee, LEADER Trial Investigators. Liraglutide and cardiovascular outcomes in type 2 diabetes. N Engl J Med. 2016; 375(4): 311-322, doi: 10.1056/NEJMoa1603827, indexed in Pubmed: 27295427.

42. Marso SP, Bain SC, Consoli A, et al. SUSTAIN-6 Investigators. Semaglutide and cardiovascular outcomes in patients with type 2 diabetes. N Engl J Med. 2016; 375(19): 1834-1844, doi: 10.1056/ NEJMoa1607141, indexed in Pubmed: 27633186.

43. Husain M, Birkenfeld AL, Donsmark M, et al. PIONEER 6 Investigators. Oral semaglutide and cardiovascular outcomes in patients with type 2 diabetes. N Engl J Med. 2019; 381(9): 841-851, doi: 10.1056/NEJMoa1901118, indexed in Pubmed: 31185157.
44. Gerstein HC, Colhoun HM, Dagenais GR, et al. REWIND Investigators. Dulaglutide and cardiovascular outcomes in type 2 diabetes (REWIND): a double-blind, randomised placebo-controlled trial. Lancet. 2019; 394(10193): 121-130, doi: 10.1016/S01406736(19)31149-3, indexed in Pubmed: 31189511.

45. Heerspink HJL, Stefansson BV, Chertow GM, et al. DAPA-CKD Investigators. Rationale and protocol of the Dapagliflozin And Prevention of Adverse outcomes in Chronic Kidney Disease (DAPA-CKD) randomized controlled trial. Nephrol Dial Transplant. 2020; 35(2): 274-282, doi: 10.1093/ndt/gfz290, indexed in Pubmed: 32030417.

46. Herrington WG, Preiss D, Haynes R, et al. The potential for improving cardio-renal outcomes by sodium-glucose co-transporter-2 inhibition in people with chronic kidney disease: a rationale for the EMPA-KIDNEY study. Clin Kidney J. 2018; 11(6): 749-761, doi: 10.1093/ckj/sfy090, indexed in Pubmed: 30524708.

47. Perkovic V, Jardine MJ, Neal B, et al. CREDENCE Trial Investigators. Canagliflozin and Renal Outcomes in Type 2 Diabetes and Nephropathy. N Engl J Med. 2019; 380(24): 2295-2306, doi: 10.1056/NEJMoa1811744, indexed in Pubmed: 30990260.

48. Canagliflozin - Center for Drug Evaluation and Research https://www.accessdata.fda.gov/drugsatfda_docs/ nda/2019/204042Orig1s032Approv.pdf accessed 30.04.2020.

49. A Research Study to See How Semaglutide Works Compared to Placebo in People With Type 2 Diabetes and Chronic Kidney Disease (FLOW) - clinical trials. https://clinicaltrials.gov/ct2/show/ NCT03819153. accessed 30.04.2020.

50. Davies MJ, D'Alessio DA, Fradkin J, et al. Management of Hyperglycemia in Type 2 Diabetes, 2018. A Consensus Report by the American Diabetes Association (ADA) and the European Association for the Study of Diabetes (EASD). Diabetes Care. 2018; 41(12): 2669-2701, doi: 10.2337/dci18-0033, indexed in Pubmed: 30291106.

51. Gaede $\mathrm{P}$, Vedel $\mathrm{P}$, Parving $\mathrm{HH}$, et al. Intensified multifactorial intervention in patients with type 2 diabetes mellitus and microalbuminuria: the Steno type 2 randomised study. Lancet. 1999; 353(9153): 617-622, doi: 10.1016/S0140-6736(98)07368-1, indexed in Pubmed: 10030326.

52. Buse JB, Wexler DJ, Tsapas A, et al. 2019 update to: Management of hyperglycaemia in type 2 diabetes, 2018. A consensus report by the American Diabetes Association (ADA) and the European Association for the Study of Diabetes (EASD). Diabetologia. 2020; 63(2): 221-228, doi: 10.1007/s00125-019-05039-w, indexed in Pubmed: 31853556.

53. 2020 Guidelines on the management of diabetic patients. A position of Diabetes Poland. Clinical Diabetology 2020; 9(1): 1-101. 